\title{
The Opera Experience: Performing a Vibrato with the Audience
}

\author{
Pre-conditions, strategies and the experience
}

DOI 10.1515/irsr-2015-0013

Received: December 1, 2014; Accepted: February 15, 2015

\begin{abstract}
Audience development is a key issue in the cultural sector, so opera house managers and policy makers need to understand how and why opera goers enjoy an opera. Our research, which investigates opera enjoyment, is framed in the social constructivist paradigm and draws on interview data collected from 15 informants. Results suggest that certain pre-conditions are necessary to be able to enjoy an opera, mainly, being cultivated and actively acquiring a liking for the genre. As for strategies to prepare for an upcoming performance, some respondents approached it as a 'special day', while others viewed it as a 'cultural experience'. For all our respondents, the experience was an emotional one. We conclude the article by discussing the implications of the results of our research.
\end{abstract}

Keywords: audience development, opera experience, opera enjoyment, opera houses management.

\section{Introduction}

In recent years, audience development has become an important issue within the cultural sector. Evidence is the fact that the European Commission has included it in the Creative Europe Programme 2014-2020 (European Commission, 2013). The specific case of opera is an extreme example, since it is one of the most expensive performing art genres, and also attracts a minority, and mostly older, audience.

\footnotetext{
*Corresponding author: Macarena Cuenca: macarena.cuenca@ deusto.es

Jordi López-Sintas: jordi.lopez@uab.es

Ercilia García-Álvarez: mariaercilia.garcia@urv.cat
}

In Spain, a 2011 survey of cultural habits and practices revealed that only $2.6 \%$ of the population had attended an opera in the previous year (Ministry of Culture, 2011). This contrasts greatly with theatre attendance (19\%), and also with attendance at classical music concerts $(7.7 \%)$, and dance/ballet performances (6.1\%) (Ministry of Culture, 2011). Trends are similar in Europe (Eurostat, 2007).

As mentioned, opera is a minority interest, and the average age of opera goers is high, with people under 55 years old underrepresented and those over 55 overrepresented (Ministry of Culture, 2011). Agid and Tarondeau (2011), in their international comparative study of opera houses and their management, reported that the average age of opera goers in most countries was between 50 and 60 years old.

In view of these data, opera houses have invested great efforts in rejuvenating their audience in recent years. Much remains to be done, however, as attendees aged over 55 years continue to be overrepresented (Doublet 2003). Funding agencies and opera house management are particularly interested in novel cultural policies aimed at broadening and rejuvenating the opera audience base. However, required - over and above sociodemographic data - is more and better knowledge of opera goers and their enjoyment of opera as leisure experience. In this article we report our research into opera consumption and describe how and why people enjoy opera productions.

\section{Theoretical framework}

\section{The transformation: opera as highbrow culture}

A performed opera is culturally complex, as production relies on many different roles, among them the composer, musicians, singers and chorists under the direction of the conductor, on-stage singers and actors, the staging manager in charge of the stage, wardrobe, props, etc. For the same musical composition, the libretto, orchestra, 
choir, singers, production, etc, all can vary enormously, so any given opera production is, in fact, a unique creation that will be more or less innovative depending on the novelty of different elements. Just how an opera is produced and presented is a decision that will have consequences for how, why and by whom it is consumed. To use the language of film, all productions based on a single musical composition are remakes. Opera is probably the cultural expression that adopts most different forms. It is hardly surprising, therefore, that its social value and its classification as popular or highbrow culture has changed since it emerged as an art form in Florence in the sixteenth century (Alier, 2004).

Levine (1988) traced the historical origins of the hierarchical classification of cultural expressions as highbrow and lowbrow, concluding that the distinction was drawn in the nineteenth century and that it tends to change over time. Research published to date suggests that the current poor opera attendance figures are the result of the marginalization of opera as a popular social activity in the same century (Storey, 2003). McConachie (1988) and DiMaggio (1992) have described how, in New York between 1825 and 1850 and in Boston between 1850 and 1900, elite social groups developed a set of social strategies that gradually marked opera off from the everyday world of popular entertainment; a similar process unfolded in Europe (Storey, 2006). First, the social elites separated opera from theatre by creating organizational forms that they controlled and governed. Second, the same social elites simultaneously marked off clearly defined boundaries between art and entertainment; for instance, opera entrepreneurs insisted that only foreignlanguage opera met the standards of art and so only this kind of opera would be programmed at the opera houses under their control (McConachie, 1988). Finally, a proper way of consuming opera was imposed as a code of behaviour (McConachie, 1988), that is, as a new etiquette of appropriation. These three strategies, which DiMaggio (1992) called entrepreneurship, classification, and framing, worked together to demarcate opera from entertainment for the masses.

However, when the social elites found they could not finance their opera houses they asked governments to support the cost of opera productions. This opened up a debate about whether an elitist cultural form should be supported by society. Social elites did succeed in their effort to receive subsidies from governments, but at a price: they lost control over opera productions, and their power to classify opera productions as art and to impose strict behaviour codes on audiences was restricted. Public funding of opera houses, in fact, undermined the three strategies deployed by the social elites to convert opera into a non-popular form of high culture. In the face of this erosion, opera house managers have become interested in knowing more about their audiences.

\section{The study of opera audiences}

The three strategies described by DiMaggio (1992), namely, entrepreneurship, classification, and framing, have transformed opera publics by reducing the social base and by raising a cultural capital barrier to the appreciation and enjoyment of opera (Tambling, 1987). Now that opera houses have an interest in broadening their audience base, they find that new potential opera goers need to bridge the cultural barriers raised during the nineteenth century. Studies of opera audiences have addressed different aspects of opera, including performance quality, reasons for attending an opera, satisfaction with performances, and, more recently, the experience of going to the opera.

A study of performance quality suggests that quality evaluations by experts and non-experts are reliable and also very similar (Boerner \& Renz, 2008), although experts were found to understand specific aspects of an opera performance better than non-experts. A study of the determinants of artistic quality suggests that individual opera components, and particularly the fit between music and staging components, contribute most to a judgement of quality (Boerner \& Jobst, 2008), with non-experts attributing less importance to the musical dimension and more to the staging dimension.

Studies of motivations for attendance have endeavoured to uncover what drives audience behaviours. Results so far suggest that the main motivations are three, namely, social hedonism, intellectual stimulus, and emotional stimulus (Bouder-Pailler, 1999; Tajtáková \& Arias-Aranda, 2008; Dobson, 2010). Other researchers have studied barriers as perceived by non-attenders, finding that the main ones are a fear of boredom, lack of knowledge, and a lack of interest in opera and ballet among peers (Tajtáková \& Arias-Aranda, 2008). Summarizing previous research on motivation, Espinola and Badrinarayanan (2010) developed a conceptual framework based on three properties that explained attendance at live events: 1) cognitive abilities (analysing, remembering, and cognitive effort); 2) category enthusiasm (i.e., high involvement); and 3) category knowledge (both objective knowledge--what is actually known by the consumers--and subjective knowledge--consumers' self-assessment of their knowledge). In their framework, the three factors affect the sacralization of the cultural expression, understood as the opposite to profanation along a continuum between the 
two (Belk, 1989); however, it is knowledge, in combination with the subjective norms of audiences, which influences the intention to go to the opera.

Interest has also focused on the satisfaction construct, which measures the value delivered to customers, and also acts as a predictor of repetitive behaviour. It is defined as the difference between what audiences obtained and what they expected to obtain. Usually satisfaction is split between the actual performance and the peripheral experience. However findings suggest that audiences obtained value, not satisfaction, from these two dimensions, with value - the difference between what one expects and what one obtains - affecting satisfaction (Hume \& Mort, 2008). Hence, different expectations will produce different kinds of satisfaction, as Jobst and Boerner (2011) have found in their study of the antecedents of satisfaction.

Finally, Radbourne and coworkers (Radbourne et al., 2009; Radbourne et al., 2010a; Radbourne et al., 2010b) explored the nature of the audience's experience and the elements which could enhance or detract from it, particularly sensations and emotions. The responses were also common to regular audiences and to non-attenders, suggesting that performing art experiences could be split into four components: knowledge/learning; authenticity; risk and collective engagement.

\section{Opera enjoyment research}

Studies of the social life of opera suggest that opera house managers and governments are both interested in widening the social base of opera audiences. However to achieve this aim, a better understanding is needed regarding how and why audiences enjoy an opera production. Studies developed under frameworks that describe consumer behaviour have addressed the issues of quality judgements, audience motivations, satisfaction determinants, and experiences, but only one study has described and explained how and why audiences enjoy opera performances, namely, Benzecry (2009), who studied passionate fans' enjoyment of opera. However, here we are interested in describing and explaining how and why different audiences - not just enthusiasts - enjoy opera performances.

\section{Methodology}

\section{Epistemology and theoretical framework}

We framed our research in the constructivist paradigm (Lincoln and Guba, 1994), which suggests that there is no universal way of enjoying a social production awaiting discovery (Geertz, 1981 [1973]; Schwandt, 1994). Rather, human beings construct the way they enjoy an opera experience, and try to make sense of it through interactions with other people and objects in the context in which the social phenomenon occurs (Crotty, 1998).

From among the different possible theoretical perspectives, our research aim led us to frame our study in terms of symbolic interactionism (Blumer, 1966, 1986). This theoretical perspective proposes that individuals interact with objects and other individuals according to meanings produced in previous interactions and according to the cultural codes of individuals (Blumer, 1966, 1986). Thus, the opera experience is built (Blumer, 1966) from the meanings that opera productions hold for the individual, produced as the individual interacts symbolically with other individuals and objects before, during, and after the opera experience, and then interpreted according to his/ her cultural code.

\section{Informants and data collection}

We started by selecting opera goers who, in the previous year, had attended at least one opera production. According to the Spanish 2010-2011 Survey of Cultural Practices and Habits (Ministry of Culture, 2011), fewer than 3 in 100 Spaniards attended an opera at least once in 2009; consequently, we used the snowballing strategy (Patton, 2002) to access further enthusiasts, that is, enrolled informants recruited further informants who had attended an opera performance. Theoretical sampling guided the screening of additional informants. Our final sample consisted of 12 opera goers who were heterogeneous in terms of age, gender, and occupation, but homogeneous in terms of social class (occupation was used as a proxy) and education level, and with some musical background, and three artistic directors of major opera houses in Spain (see Table 1).

We conducted in-depth open-ended interviews with the 12 opera goers during the first half of 2009, in different contexts (home of the interviewee or interviewer, cafes, or offices) in the province of Barcelona (Spain). We designed an interview protocol that was flexible enough to adapt to the themes emerging from the narratives and from the analysis. Our protocol covered the social and individual dimensions of the opera experience before, during, and after the performance, and also took into account the sociocultural backgrounds of the interviewees. The interviews were conducted in Spanish or Catalan (since Catalonia is a bilingual region), lasted between 60 and 105 minutes, were digitally recorded, and were 
Table 1. Description of informants

\begin{tabular}{|c|c|c|c|c|c|}
\hline Name & Sex & Age & Education & Music Background & Occupation \\
\hline 1 Marc & M & $>40$ & University & Instrument & Employed, not specified \\
\hline 2 Emma & $\mathrm{F}$ & $\leq 40$ & University & Instrument (piano) & Employment consultant \\
\hline 3 Esther & $\mathrm{F}$ & $>40$ & University & Singing & Singing teacher \\
\hline 4 Joan $A$ & M & $>40$ & University & Composition & Music school manager \\
\hline 5 Laia & $\mathrm{F}$ & $\leq 40$ & Upper Secondary & Instrument (guitar) & University student \\
\hline 6 Montse & $\mathrm{F}$ & $>40$ & University & Instrument (piano) & Secondary school teacher \\
\hline 7 Rosa & $\mathrm{F}$ & $>40$ & University & Not known & Nurse \\
\hline 8 Carles & $M$ & $\leq 40$ & University & Instrument & Employed, not specified \\
\hline 9 Carlos & M & $\leq 40$ & University & Instrument (piano) & Computer engineer \\
\hline 10 Chema & M & $\leq 40$ & University & Instrument & Employed, not specified \\
\hline 11 Pepa & $\mathrm{F}$ & $\leq 40$ & University & Instrument & Musician \\
\hline 12 Nuria & $\mathrm{F}$ & $>40$ & University & Singing & Doctor \\
\hline 13 Gerard Mortier & M & $>40$ & University & Not known & Artistic director (Teatro Real, Madrid in 2011) \\
\hline 14 Jon Paul Laka & M & $>40$ & University & Not known & Artistic director (ABAO-OLBE, Bilbao in 2011) \\
\hline 15 Joan Matabosch & M & $>40$ & University & Not known & $\begin{array}{l}\text { Artistic director (Gran Teatre del Liceu, Barcelona } \\
\text { in 2011) }\end{array}$ \\
\hline
\end{tabular}

transcribed verbatim with the help of speech recognition software (Dragon Naturally Speaking). Respondents were guaranteed their anonymity, and were informed of the purpose of research and of their right to terminate the recording if they wished. In 2011 we interviewed the artistic directors of Spain's three major opera houses in order to contrast enthusiasts' information with that provided by professionals. Supporting documentation was collected consisting of news reports, reports, specialist press articles, and opera houses website information regarding productions and audiences.

\section{Analysis}

The corpus of data was analysed using inductive thematic analysis (Mayring, 2000). The analysis started with open coding - which allowed us to create initial codes describing the experiences of our interviewees before, during, and after their opera experiences - and with analytical memos. By means of constant comparisons between the incidents in each code and the theoretical memos, we generated analytical categories and documented their properties. This process enabled us to develop analytical categories as follows: (1) conditions for enjoying opera (biography, learning to like opera, and being cultivated); (2) strategies used to enjoy opera (constructing the experience as a special day, or as a cultural experience, selecting a suitable companion); and (3) description of the opera experience (the emotional experience of live opera, and the shared and individual experience).

We continued coding selectively to refine the analytical categories and integrate the interviewees' descriptions of their experiences. In this phase, having determined the central research category to be 'process to enjoy an opera production', we launched a process of abstraction to organize the analytical categories around this concept. The findings of this analytical process represented instances of the way individuals extracted enjoyment from opera productions (Crotty, 1998).

The analysis was performed with the help of the Dedoose Desktop App for collaborative computeraided qualitative data analysis (Sociocultural Research Consultants, 2013). We followed the analytical procedure for coding and forming categories described by Kelle (1995) when using data analysis software, and the memo writing guidelines described by Strauss (1987). The Dedoose system, based on memoranda and visual software tools, was especially useful for our analysis, in that it facilitated the construction and management of the repository of common descriptions of experiences, yielding segments of text linked to codes and codes linked to analytical categories. 


\section{Findings}

The narratives of our informants suggest that there is no unique way to enjoy opera; rather, the different ways of enjoying opera are associated with the biographies of the informants, the way they learned to like the genre, and their knowledge of opera in terms of academic or artistic disciplines associated with it. These pre-conditions interact in terms of defining strategies for enjoying operas, with some respondents making preparations to enjoy what they consider to be a very 'special day', and with other respondents prioritizing the 'cultural experience'. The descriptions of the operatic experience reveal that it has at least two dimensions, one ritual (or social) and the other individual: both are emotional nonetheless, with the many facets of an opera interacting to create the magic of a live performance in which the enthusiasts participate.

\section{Conditions for enjoying opera}

\section{Biography}

The descriptions of the experiences of the interviewees reveal how they have different relationships with the world of opera. Some have spent their whole life in contact with the genre, while others developed their interest in adulthood. Attendance frequencies also vary. Montse and Rosa, for example, have season tickets for the Liceu opera house in Barcelona, and attend all the operas scheduled throughout the year. Nuria has no season ticket, so she attends occasionally; above all, she tries to go to a performance wherever she travels for her work. Joan concedes that the last opera he attended was in 2006 in France, and that he only cares to attend if the opera is in some way new or novel.

Our interviewees all belong to the middle classes, according to their occupation and education, and all are actively employed, except Laia (18 years old), who has just started university. However, their ages, education, and careers are very different. Some work in the world of opera, as in the case of the three artistic directors; others have a career in music, like Esther, a singing teacher, and Joan, a composer and music school manager; and the remaining respondents have unrelated and very diverse professions, e.g. secondary language and literature teacher (Montse), employment consultant (Emma), nurse (Rosa), and computer engineer (Carlos).

Despite their different biographies, the informants agree regarding two necessary pre-conditions for enjoying the operatic experience. The first is that one has to actively learn about opera and learn to like the genre. The second is that one must be cultivated and have the prior accumulated knowledge necessary to enrich the experience and interpret the work.

\section{Learning to like opera}

The social visibility of opera is poor. It is never featured on the front pages of the press or on prime-time television and it is not included in school curricula. Furthermore, one needs to experience opera live, as the broadcast opera experience is not comparable. Esther described the sensation of 'a sound wave impact on the body (...) that would not be transmitted by a device'. But, apart from the visual and sound effects, live opera is also an experience shared with the rest of the audience. Silence, tension, applause, boos, etc, are all part of the experience. Montse explains this very graphically:

\footnotetext{
Opera is opera and you have to see it live. It isn't the same to smell cured ham compared to eating it, right? Well, it's like that. Living the moment, in complete silence, maybe, because the aria is really famous and everyone knows it, you get goose pimples when you hear it sung, right? That can only be experienced live.
}

However, one's decision to go to an opera performance the first time is not a straightforward or obvious decision. As Laia pointed out, 'information on the world of opera does not come to you if you do not look for it ...'. In addition, opera has an elitist image, which also acts as a potential barrier to entry to this world. Jon Paul Laka, artistic director of ABAO-OLBE says, 'you go with someone who takes you, or someone who invites you, else you end up mingling with a public that transmits the feeling that you do not belong.'

Several interviewees alluded to the fact that you have to learn to like the opera. Nuria explains that enjoying opera 'is not straightforward or simple', and she herself, now a big fan, acknowledges her initial scepticism. Marc explains how his family frequently went to the opera when he was young, but he was not interested; however, as he got older his 'desire to see opera increased'. Laia also points out that enjoyment increases as operatic experiences accumulate: 'If you really like and frequently go to the opera, it's a drug that grows on you and you keep going back'. 


\section{Being cultivated}

Once the initial barriers are overcome, the operatic experience is conditioned by the prior knowledge accumulated by the enthusiast. Having background knowledge conditions interest in particular types of opera, and in different elements of the performance. Esther, a singing teacher, illustrates the former: she describes how her interest has evolved from verismo to opera with a 'purer treatment of the voice, the early bel canto and everything classical'. Her career as a singing teacher is clearly reflected in the evolution of her operatic tastes. Having background knowledge also conditions interest in the different arts that converge in opera, offering as it does the possibility to focus on elements as varied as music, voice, stage, costumes, lighting, text, choreography, etc, with personal and professional backgrounds playing a role. Thus, Montse, a language and literature teacher, says: 'Having studied philology, and with an interest in literature, I also look for that in the text of the opera, and liking both music and literature, I especially look out for that connection'.

Furthermore, familiarity with the opera being performed is important. According to Montse:

The more you know the more you enjoy it, of course, the more you can appreciate it. If you know how to play the piano, and you know how to play a certain sonata, when you hear it, if a trill has been skipped, you go, hey, what's going on? But the person who doesn't know that, they'll never know what was missed...

Carles believes that one must be cultivated to enjoy the opera: 'The new rich, do not have enough [culture], are not sufficiently educated to enjoy it, so they get bored, and if one day they do go, the next day they don't return.' In relation to his own evolution in the enjoyment of opera, Carles recognizes that 'increasingly I understand more, more details and things, and I see more ... see more substance where sometimes it seems that there is none'.

\section{Strategies for enjoying opera}

Opera is a very complex discipline, the enjoyment of which needs to be cultivated. In this all the informants agree, although they differ on how to do this: some prepare the upcoming opera visit as if for a very special day, whereas others view it primarily as a cultural experience. These two perspectives define their opera-going strategies. All informants agree, however, in the desire to be accompanied, yet concede that they often attend alone.

\section{A special day}

Some of our respondents considered that the visit to the opera should be prepared as a very special day. Rosa, a nurse, describes how the event seemed 'as if it was some kind of festival or a major holiday [laughing], you know, something different and special'. These informants develop a ritual to distinguish the operatic experience from an everyday routine. There is a perception that this is a time of relaxation, as Pepa, a professional musician, tells us: 'At the very least I'll be well on time, and well, maybe even take a walk beforehand. If going to the Liceu, one may as well take a stroll along the Rambla [street], sit in a cafe.'

Whether going to the opera in their home town or when on a trip abroad, the informants reserve tickets well in advance. Pepa took advantage of a trip to New York to see one of her favourite operas: 'I really wanted to see the opera and it was very special, because the opera ... as well as seeing it in a place like this, it's one of the operas that I like most, so it's savoured even more.'

When the visit to the opera is special, it seems necessary to know the role one should play in the ritual to make it special. One option is to listen to the talk given in the foyer beforehand, as Rosa, tells us, as preparation: 'That man, that man who works in the foyer, he was the one who told me, it's like this and there's the entrance, you'll see it's lovely ... he explained everything and of course you go much better informed, you know about the plot and the music.'

There is also preparation at home, as Marc tells us: 'You read about the plot ... whether you find it interesting or not ... so as not to be at a loss when the opera is on, to learn a little, yes, but not in depth.' Or, as Emma, a pianist now working as an employment consultant, tells us: 'I usually read the libretto beforehand, yes.' If the staging of the opera is different - for instance, when she saw The Marriage of Figaro in English - she prepares even better. 'It was on the news on TV3, I saw how the scenery was being put into place and everything, and how it was like, the director, I don't remember who it was, how he brought something new, the set design, representation, the story.'

Laia, younger than the other respondents, also seeks out information on the opera she plans to see. 'Usually if I have time I read the reviews, and well, it's a way to find out what people have said about the opera and such.' When there is no time, as Montse tells us, going to the opera is almost like an obligation: 'I have to admit that sometimes it feels like it's high time I went to the Liceu, so I go, but I have so much work that I have no time to look at anything.' 
For these informants, the opera evoke a certain veneration regarding what they will witness. 'You feel a kind of reverence for what'll happen there,' Esther says. To symbolize that it is a special day you 'dress up a bit', says Pepa. 'You tidy up,' Marc tells us, and laughs before continuing: 'No need to wear a tie, but yes, dress a bit better, not to draw attention.' Esther further points out that 'going to the Liceu is not the same as going to the movies or Burger King, or whatever.' She laughs and continues: 'So people are more into the ritual, I think ... one breathes atmosphere.'

\section{A cultural experience}

'Yes, for me it's more a matter of culture, I dress like I usually dress, not in any way special, I probably wouldn't wear jeans, but no, I'd not dress in any ... special way.' This is how Nuria perceives her visit to the opera, contrasting with the alternative perception of the day as special. For these respondents there is no ritual. Chema and Carles also say that they 'act quite normally', and do not attach any special importance to the day.' Nuria is never sure that she will even have a ticket: 'The truth is that you hope you are lucky there, so you can get tickets'. Sometimes she has to queue for ages with no guarantee that she will get a ticket, as when she waited in line two hours to see the Garnier production of Platée by Jean Philippe Rameau. 'But in the end I got a good seat, I paid a bit more, but with the discount for buying two hours before, the truth is I could get a good seat and enjoy it, that's important.'

Preparing the upcoming opera visit properly, Nuria tells us, involves:

...not only knowing the story but also the period, the composer, the idea to be conveyed, specific style aspects. And that's interesting, because when you are listening and watching, you recognize things, and you notice things, and probably if I had gone with less knowledge, I don't know if I'd have noticed so much.

For Carles, like Nuria, time is always tight, which is why he never goes to the foyer; he explains, however, that 'I usually seek information on the plot, and especially if there is anything I need to know about the author, or the historical context.' He continues: 'If I like the opera, or a singer or whatever, I'll look for information online, or look up the discography.'

When the opera is known, the expectation is less, Carles tells us. 'But if I don't know it, I'm a little more open, expectant.' This particularly happens with contemporary operas, according to Nuria, whose most recent experience, which she prepared well, was like an explosion of sight and sound:

\begin{abstract}
The truth is that I loved it; the truth is that it was ... I went well prepared. It was ... interesting, and for me it was a new work. This maybe has to be done more for more contemporary works, huh? Because the others are so well known, there are stereotypes and one goes and knows the plot, and so on. They are straightforward works, musically even, you know, going to see a Baroque or Romantic work, whatever. But these contemporary works have to have other points of interest, don't they? You have to consider other elements right? Like text, set design, wardrobe, performance, you know, in that sense they're interesting, especially more recent works.
\end{abstract}

\section{A suitable companion}

Perhaps because of its complexity - that 'explosion of sound and vision' - the opera is enjoyed with or without companions. As Nuria says: 'The pleasure is being there and seeing it, you do not need one [companion], people don't affect the experience. I'm perfectly happy to go alone.' Chema is more expressive when describing an ideal companion. 'Well, they must like it, a lot and enjoy it, a lot, and mustn't talk during the performance.' He laughs and continues: 'They mustn't bother you and are quiet.'

All agree, however, that it is better to go with someone. As Carlos told us: 'You know, you can comment on it with the person you go with. If you go accompanied, you talk about it on the way and swap knowledge, right? About the opera in question.'

\section{Description of the opera experience}

\section{An emotional experience}

Opera typically arouses intense emotions. Our informants, classifying it as a beautiful experience, depict varying levels of emotion depending on their biographies, and their musical and cultural knowledge. Esther, for example, preparing her upcoming opera visit as a special day, tries to enjoy the experience to the utmost. '(...) I concentrate on the experience, because it's like a gift (...) in terms of time and money, so, I try to live the pleasure of the experience to the full, I turn off the phone, no one can locate me, and I focus on where I am.'

Nuria, however, for whom opera is a cultural experience, describes how different aspects of the opera interact to form a complete work of art that creates an exceptional moment of pleasure and enjoyment: 
(...) A moment of pleasure ... I like to listen, especially to listen, let myself be wrapped in what this music conveys, but I'm also really interested in the work as a whole, and so I visually examine all elements, how the set is made, how it is assembled, how the work is staged, how the singers do what they do, it's basically escape, a moment of being immersed in an artwork.

Rosa says that she feels happy during the performance, but also experiences a more long-lasting feeling of happiness once it is over. When one achieves what Nuria calls ecstasy, the end of the opera means returning from that other magical world back to everyday life. If the conditions of the operatic production are right, the performance is like a time machine that transports one to another era, as Montse commented regarding a Monteverdi opera she attended: 'I felt transported ... you know, you suddenly realise, so many centuries ... and here I am, listening here today. That is the emotion.'

One's first time at a live opera will have either a positive or negative impact on one's subsequent enthusiasm for opera. If one is overwhelmed by the performance it becomes an unforgettable experience and so maintains one's enthusiasm. This becomes important when it comes to choosing the opera - 'Madame Butterfly had a major impact on me,' says Laia - and choosing a companion who enhances both the entertainment and enjoyment. Rosa explains that, on her very first visit to the opera, encouraged by a friend, she obtained autographs and was photographed with the singers, and although many years have passed she still has a vivid memory of this experience that has kept her 'connected'.

To enjoy the opera one's emotions must be aroused. This is only possible if one is cultivated and prepares each opera visit. Knowledge ensures an emotional enjoyment. As Laia states:

I think more than anything it is emotion and feeling. Anyone who wants to go to hear an opera, if it really motivates them to hear and feel something, that person is just as capable a critic as the most erudite scholar in the world. I think everyone, if they feel motivated and hear something, can appreciate it.

However, according to the interviewees not all operas are the same. Some are pure emotion, whereas others have an intellectual component that needs to be understood to enable the link with the emotions. Such operas require one to actively listen, and to have the musical information necessary to understand the depth of the associations between the cognitive and emotional dimensions. As Jon Paul Laka expressed it:

As in literature or painting, there are pictures and operas that are very accessible and others less so ... It has, perhaps, a com- ponent of intellectual analysis that connects to the emotional part, no doubt about it, but one needs training. You cannot send anyone who has never been to the opera to see, say, Debussy's Pélleas et Melisande. I doubt that a person who goes to the opera for the first time to see that work will get excited by the experience, right? But, they will, of course, for a good Turandot or Traviata production, right?

Knowing the work and going prepared reveals the beauty contained in the opera as a whole as an explosion of the senses. As Nuria says:

You recognize things and you notice things in the work that you probably wouldn't have noticed and so it's especially beautiful, right? Not only the music, but everything, right? It's like an explosion of sight, of sound, right?

The opera is considered to be a very complete work, a spectacle that combines different disciplines, which, as Joan points out, makes it perfect. Because it encompasses so much, its potential to thrill you and make you feel special is exceptional, as Pepa points out. But even though one likes opera, if the performance or production is poor, according to the viewpoint of the enthusiast, or if a work contains too much information or is not easy to interpret, they may bore the person but not necessarily discourage them from attending another production.

\section{Individual versus shared experiences}

Respondents held different opinions regarding the individual or shared experience. For some, the individual aesthetic experience prevails, as Laia reveals:

When you're at the performance, it's you listening to the opera, and the people who are around you do not really affect you ... Yes, it's good to go with someone, so that, during intermissions, you can comment on the work and such, but really .... when you are watching the opera I think people next to you do not affect you.

Important for others is the social experience, which may have different meanings: a social act, or an opportunity to engage with others, or to participate in a ritualistic experience in which people share expectations about what is about to happen, their love of music, etc. The shared experience can complement and amplify the individual experience, as Esther explains:

Well, first and foremost, the music, but then also the atmosphere, being there at the Liceu ... there is that particular sense of atmosphere that permeates the crowd which makes the experience even more special ... the love of music, respect for what will 
happen there, it's like a ritual, to listen to something great and grand, it is also a very ritualistic experience, going to the opera, just another kind of experience.

\section{Discussion and conclusions}

The analysis conducted suggests that the different biographies of our informants are reflected in different processes of enjoyment. Therefore, there is not a single way to enjoy opera. We have described two enjoyment strategies that lead to different experiences, which vary depending on the strategies each viewer select to prepare the enjoyment of the next opera. But in order to build a strategy of enjoyment, the potential viewer must overcome a first condition: enter the opera world.

The conditions for enjoying an opera performance indicate that the entrepreneurship, classification and framing strategies (DiMaggio, 1992) put in place during the nineteenth century have been successful. Interviewees agree regarding the need to be cultivated to enjoy opera, irrespective of the strategy chosen to prepare for an upcoming performance. The strategy of preparing an upcoming visit to the opera as a special day would seem to be the outcome of framing. It is not surprising that Boerner and Renz (2008) found a high level of agreement between experts and non-experts in their judgments about the quality of performances, as it would seem that being cultivated is a necessary pre-condition for enjoying the genre. In fact, our research suggests that the way Boerner and coworkers (Boerner and Jobst, 2008; Boerner and Renz, 2008) measured the expertise of the individuals they surveyed reflects the conditions for enjoying opera.

Results from studies of audience motivations reflect the conditions, strategies, and experiences we have described, concretely, the interest in a particular performance and in certain genres, and going out with friends or family (Tajtáková and Arias-Aranda, 2008), the emotional, intellectual and social experience (Bouder-Pailler, 1999), and the feelings of inclusion and participation (Dobson, 2010) - which framing formerly reserved for a select few individuals (Levine, 1988; McConachie, 1988; DiMaggio 1992).

The two identified strategies that audiences follow to cultivate the next opera performance seem to be related to the sacralization of the opera category, the result of the framing strategy. According to Belk's (1989) interpretation of the sacred and the profane, the strategy of converting the day of the performance into a special day would seem to point to a treatment of opera as a sacred cultural form (the result of framing), whereas the cultural experience strategy views opera as something ordinary, if complex. For these reasons, our results suggest a modification to the model proposed by Espinola and Badrinarayanan (2010), as, given the conditions to enjoy a cultural form, personal values interact with conditions to sacralize, or otherwise, the opera; in other words, sacralization is not universal to all opera goers. These strategies also generalize Benzecry's (2009) findings about how passionate opera fans prepare for upcoming opera experiences.

As pointed out above, when researching the quality of the opera-going experience, researchers (Radbourne et al., 2009, Radbourne et al. 2010a and Radbourne et al. 2010b) have proposed decomposing it into the four components of knowledge/learning, authenticity, risk and collective engagement. Our findings suggest that knowledge - being cultivated - is a condition for enjoying opera, and that learning is the result of preparing for an upcoming opera. They also suggest that authenticity and collective engagement are components of the experience, along with emotional involvement; however, note that our interviewees never referred to the risk of not enjoying the opera. Finally, our findings, by describing different enjoyment strategies used by opera goers in general, extend those of Benzecry (2009) regarding passionate opera fans.

The sustainability of opera as a live performance requires the audience base to be broadened. To do this, opera house managers will need to remove the barriers created as a result of the entrepreneurship, classification and framing strategies described by DiMaggio (1992). A set of actions focused on removing such barriers could include segmentation of the audience and creating a renewed product for specific segments, as it has been already done for children's productions. Such segmentation would minimize the risk of disappointing audiences and would increase revenues (Laamanen 2013). But potential audiences also need to be encouraged to enter the potentially intimidating world of opera. The data suggest that almost nobody goes on their own for the first time. It is typically a regular opera goer who opens the door to the world of opera to others. Interestingly, however, for most of the regular opera goers interviewed for our research, companionship was not a conditioning factor, as many of them attended the opera unaccompanied. Nonetheless, many of them did indicate how they often attended on their own - as if to indicate a slightly negative aspect of their experience. This situation is not unique to opera goers, but has been also documented for museum visitors (Lopez, Garcia and Perez, 2014). A potentially interesting option would be to consider how to bring opera goers with similar operatic interests into contact with each other, and 
so create affinity spaces (Gee, 2004) that would improve the operatic experience of participants and would encourage attendance.

Funding: This work was supported by the Spanish Ministry of Science and Innovation under Grant ECO201129558-C02-01, and by the Generalitat of Catalonia under Grant 2014-SGR-502.

Acknowledgements: We acknowledge funding from the UAB Centre for Research and Studies in Humanities, the Spanish Ministry of Science and Innovation, and the Generalitat of Catalonia. We would also like to thank our informants for sharing with us a part of their lives. Ailish Maher assisted with the English in a version of this manuscript. We assume full responsibility for the claims made in the manuscript.

\section{References}

ABAO-OLBE. (2011) Análisis Socios 2010-11. Unpublished material. Agid, P. and Tarondeau, J. (2011) Le Management des Opéras. Comparaisons Internationales. Paris: Descartes \& Cie.

Alier, R. (2004) ¿Qué es Esto de la Ópera?: Introducción al Mundo de la Lírica. Barcelona: Ma Non Troppo.

Belk, R. W. (1989) 'The sacred and the profane in consumer behavior: theodicy on the Odyssey', Journal of Consumer Research, 16 (June), 1-38.

Benzecry, C. (2009) 'Becoming a fan: on the seductions of opera', Qualitative Sociology, 32 (2), 131-151.

Blumer, H. (1966) 'Sociological implications of the thought of George Herbert Mead', American Journal of Sociology, 71 (5), 535-544.

Blumer, H. (1986) Symbolic Interactionism: Perspective and Method. Berkeley [etc.]: University of California Press.

Boerner, S. and Jobst, J. (2008) 'The perception of artistic quality in opera - results from a field study', Journal of New Music Research, 37 (3), 233-245.

Boerner, S. and Renz, S. (2008) 'Performance measurement in opera companies: comparing the subjective quality judgement of experts and non-experts', International Journal of Arts Management, 10 (3), 20-29.

Bouder-Pailler, D. (1999) 'A model for measuring the goals of theatre attendance', International Journal of Arts Management, 1 (2), 4-15.

Crotty, M. (1998) 'The Foundation of Social Research: Meaning and Perspective in the Research Process', London: Sage Publications.

DiMaggio, P. (1982) 'Cultural entrepreneurship in nineteenth-century Boston. Part l', Media, Culture and Society, 4, 33-50.

Dobson, M. C. (2010) 'New audiences for classical music: the experiences of non-attenders at live orchestral concerts', Journal of New Music Research, 39 (2), 111-124.

Doublet, G. (2003) 'Opéra: nouveau public, nouvelles pratiques'. In: O. Donnat and P. Tolila (eds.) Le(s) Public(s) de la Culture, pp. 215-234, Paris: Presses de Sciences Po.
Espinola, A. and Badrinarayanan, V. (2010) 'Consumer expertise, sacralization, and event attendance: a conceptual framework'. Marketing Management Journal, 20 (1), 145-164.

European Commission (2013) Press release: Commission welcomes approval of Creative Europe programme by European Parliament. Available from: http://europa.eu/rapid/pressrelease_IP-13-1114_en.htm (consulted 12 January 2014).

Eurostat (2007) Cultural Statistics. Luxembourg: Office for Official Publications of the European Communities. Available from: http://epp.eurostat.ec.europa.eu/cache/ITY_OFFPUB/ KS-77-07-296/EN/KS-77-07-296-EN.PDF (consulted 5 October 2013).

Fundació Gran Teatre del Liceu (2013) Memòria 2011/2012. Barcelona: Fundació del Gran Teatre del Liceu. Available from: http://www.liceubarcelona.cat/fileadmin/PDF_s/Memories/ memoria11_12.pdf (consulted 5 November 2013).

Gee, J. P. (2004) Situated Language and Learning: A Critique of Traditional Schooling. New York: Routledge.

Geertz, C. (1981[1973]) La Interpretación de las Culturas. Barcelona: Gedisa.

Hume, M., and Mort, G. S. (2008) 'Satisfaction in performing arts: the role of value?', European Journal Marketing, 42 (3/4), 311-326.

Jobst, J. and Boerner, S. (2011) 'Understanding customer satisfaction in opera: first steps toward a model', International Journal of Nonprofit and Voluntary Sector Marketing, 16, 50-69.

Kelle, U. (1995) Computer-Aided Qualitative Data Analysis: Theory, Methods and Practice. London: Sage.

Laamanen, J.-P. (2013) 'Estimating demand for opera using sales system data: the case of Finnish National Opera', Journal of Cultural Economics, 37, 417-432.

Levine, L.W. (1988) Highbrow/Lowbrow: The Emergence of Cultural Hierarchy in America. Cambridge, MA: Harvard University Press.

Lincoln, Y. S. and Guba, E. G. (1994) 'Competing paradigms in qualitative research' In: N. K. Denzin and Y. Lincoln (eds.) Handbook of Qualitative Research, pp. 215-234, Thousands Oaks, Calif. [etc.]: Sage.

López Sintas, J., García Álvarez, E. and Pérez Rubiales, E. (2014) 'Art museum visitors: interaction strategies for sharing experiences'. Museum Management and Curatorship, 39(3), 241-259.

Mayring, P. (2000) 'Forum : Qualitative Social Research Sozialforschung 2. History of Content Analysis', Forum: Qualitative Social Research. Sozialforschung, 1 (2 Art. 20).

McConachie, B.A. (1988) 'New York operagoing, 1825-50: creating an elite social ritual', American Music, 6 (2), 181-192.

Ministry of Culture (2011) Encuesta de Hábitos y Prácticas Culturales 2010-2011. Madrid: Ministry of Culture. Available from: http:// www.mcu.es/estadisticas/MC/EHC/2010/Presentacion.html (consulted 5 November 2013).

Patton, M.Q. (2002) Qualitative Research and Research Methods. London: Sage.

Radbourne, J., et al. (2009) 'The audience experience: measuring quality in the performing arts', International Journal of Arts Management, 11 (3), 16-29.

Radbourne, J., Glow, H. and Johanson, K. (2010a) 'Measuring the intrinsic benefits of arts attendance', Cultural Trends, 19 (4), 207-324. 
Radbourne, J., Johanson, K. and Glow, H. (2010b) 'Empowering audiences to measure quality', Journal of Audience and Reception Studies, 7 (2), 360-379.

Schwandt, T. A. (1994) 'Constructivist, interpretivist approaches to human inquiry' In: N. K. Denzin and Y. Lincoln (eds.) Handbook of Qualitative Research, pp. 118-137, Thousand Oaks, Calif. [etc.]: Sage.

Sociocultural Research Consultants (2013) Dedoose Version 4.5, web application for managing, analyzing, and presenting qualitative and mixed methods research data. Los Angeles, CA: Sociocultural Research Consultants, LLC (www.dedoose.com).

Storey, J. (2003) 'The social life of opera', European Journal of Cultural Studies, 6 (1), 5-35.

Storey, J. (2006) 'Inventing opera as art in nineteenth-century Manchester', International Journal of Cultural Studies, 9 (4), 435-456.

Strauss, A.L. (1987). Qualitative Analysis for Social Scientists. Cambridge: University Press.

Tajtáková, M., and Arias-Aranda, D., (2008) 'Targeting university students in audience development strategies for opera and ballet', The Service Industries Journal, 28 (2), 179-191.

Tambling, J. (1987) Opera, Ideology, and Film. New York: St. Martin's Press.

\section{Bionotes}

Macarena Cuenca, has a PhD in Leisure and Human Development and is a professor of strategy and business organisation at Deusto Business School. She is a researcher in the Leisure and Human Development research group within the Institute for Leisure Studies at the University of Deusto. Her main line of research is related to the development of cultural audiences. She currently participates in the ADESTE project, financed by the European Commission and focused on audience development. She has published in several international journals, including Arbor, Cuadernos de Gestión, Revista de Ciencias de la Educación, Journal of Cultural Management and Policy, Lusophone Journal of Cultural Studies, Quaderns Animació i Educació Social, Revista de Humanidades.

Jordi López-Sintas, has a PhD in business economics and is a full professor in marketing and consumer research at the Universitat Autònoma de Barcelona. He is the director of the Centre for Studies and Research in Humanities at the Universitat Autònoma de Barcelona, and he is the principal investigator of the Consumption, Markets and Culture research group 2009-SGR-411. He is cofounder and vice-president of ESPACUAL (Spanish Association for the Advancement of Qualitative Research). He has published in several international journals, including Poetics, European Sociological Review, Social Forces, Field Methods and Family Business Review.

Ercilia García-Álvarez, has a PhD in business economics. Serra Hunter Professor. Department of Business Management at the Universitat Rovira i Virgili. Director of the Qualitative Research in Leisure Markets and Organizations (Qualocio) research group and member of Consumption, Markets, Culture (CMC) research group of the Universitat Autònoma de Barcelona. President of the Spanish Association for the Advancement of Qualitative Research (Espacual). She has published in various international journals such us: European Sociological Review, Poetics, Social Forces, Field Methods, Family Business, Cultural Economics. 